\title{
The nucleation of the Izmit and Düzce earthquakes: some mechanical logic on where and how ruptures began
}

\author{
Michel Bouchon, ${ }^{1}$ Hayrullah Karabulut, ${ }^{2}$ Mustafa Aktar, ${ }^{2}$ Serdar Özalaybey, ${ }^{3}$ \\ Jean Schmittbuhl, ${ }^{4}$ Marie-Paule Bouin ${ }^{5}$ and David Marsan ${ }^{1}$ \\ ${ }^{1}$ Université Grenoble Alpes, Université Savoie Mont Blanc, CNRS, IRD, ISTerre, Grenoble, France. E-mail: Michel.Bouchon@univ-grenoble-alpes.fr \\ ${ }^{2}$ Kandilli Observatory and Earthquake Research Institute, Bogaziçi University, 81220, Cengelköy, Istanbul, Turkey \\ ${ }^{3}$ Tübitak Marmara Research Center, Gebze, Turkey \\ ${ }^{4}$ Université de Strasbourg, Strasbourg, France \\ ${ }^{5}$ Institut de Physique du Globe de Paris, France
}

Accepted 2021 January 26. Received 2021 January 13; in original form 2020 September 11

\begin{abstract}
SUMMAR Y
In spite of growing evidence that many earthquakes are preceded by increased seismic activity, the nature of this activity is still poorly understood. Is it the result of a mostly random process related to the natural tendency of seismic events to cluster in time and space, in which case there is little hope to ever predict earthquakes? Or is it the sign that a physical process that will lead to the impending rupture has begun, in which case we should attempt to identify this process. With this aim we take a further look at the nucleation of two of the best recorded and documented strike-slip earthquakes to date, the 1999 Izmit and Düzce earthquakes which ruptured the North Anatolian Fault over $\sim 200 \mathrm{~km}$. We show the existence of a remarkable mechanical logic linking together nucleation characteristics, stress loading, fault geometry and rupture speed. In both earthquakes the observations point to slow aseismic slip occurring near the ductile-to-brittle transition zone as the motor of their nucleation.
\end{abstract}

Key words: Earthquake source observations; Dynamics and mechanics of faulting; Transform faults.

\section{INTRODUCTION}

The $M_{\mathrm{w}} 7.6$ (www.globalcmt.org) Izmit earthquake occurred on 17 August 1999 and is still the best recorded large strike-slip earthquake to date. It ruptured the North Anatolian Fault (NAF) over a length of about $150 \mathrm{~km}$ with an average slip close to $3 \mathrm{~m}$ (Barka et al. 2002). Nearly 3 months later on 1999 November 12, the $M_{\mathrm{w}}$ 7.1 Düzce earthquake extended the rupture $\sim 40 \mathrm{~km}$ eastward with an average slip also close to $3 \mathrm{~m}$ (Akyüz et al. 2002). Some $20 \mathrm{yr}$ after their occurrence, in light of the many studies that have been carried out on these two events, we look again at their nucleation as part of a unique scenario.

\section{THE LOCATION OF THE IZMIT EPICENTRE}

'The section of the North Anatolian Fault lying near the city of Izmit, at the east of the Marmara Sea, has been identified as a seismic gap and the possible site of a future major earthquake." These premonitory words (Evans et al. 1987) refer to the designation, $20 \mathrm{yr}$ before the Izmit earthquake, of this section of the NAF as a major seismic gap by Toksöz et al. (1979). Another characteristic of this section, well known before the earthquake, was the presence of ' $a$ swarm of small earthquakes in the centre of this otherwise almost aseismic section of the NAF' (Crampin et al. 1985). A consideration of these characteristics in light of previous observations made by Dewey (1976) provides the scenario that will be followed by the Izmit rupture. As Dewey writes in 1976 concerning large earthquakes on the NAF: 'The relocated epicentres support the hypothesis that fault rupture in large and great earthquakes will begin in regions of small and moderate earthquakes; the rupture of large earthquakes then propagates into sections of the fault that normally have a low level of activity'. The Izmit earthquake began in the middle of the seismic swarm and its rupture propagated bilaterally into sections of the fault with normally little activity (Fig. 1).

Between 1978 and 1986 the Izmit swarm was extensively instrumented and studied by the British Geological Survey and the Kandilli Observatory as the in situ experimental site for a series of projects on crustal anisotropy. The area was chosen because the swarm was a localized and continuous source of small earthquakes $(M<4)$ well suited for the projects. A map of the cluster activity during one of the experiments in the summer of 1984 is shown in Fig. 2 (Evans et al. 2000). The high density of recording stations only a few kilometres apart provides a detailed image of this activity. What is remarkable is the spatial spread and scatter of the activity over a zone of about $20 \mathrm{~km}$ by $20 \mathrm{~km}$. What is most striking is that 


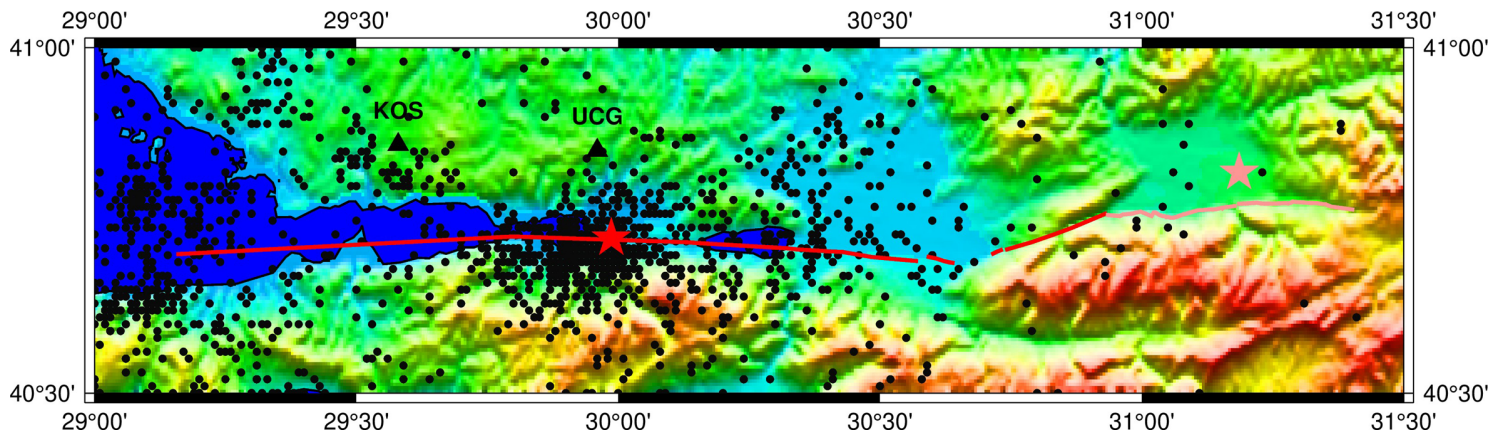

Figure 1. The 200 -km-long 1999 rupture of the North Anatolian Fault (Izmit rupture in red, Düzce rupture in pink) with the epicentres of the two earthquakes (red and pink stars). The Düzce epicentre offset with respect to the surface rupture is due to the northward dip of the Düzce segment. The dots are the seismic events in the Kandilli catalogue in the $10 \mathrm{yr}$ before the earthquakes. The locations of the two seismic stations closest to the epicentre are indicated by triangles.

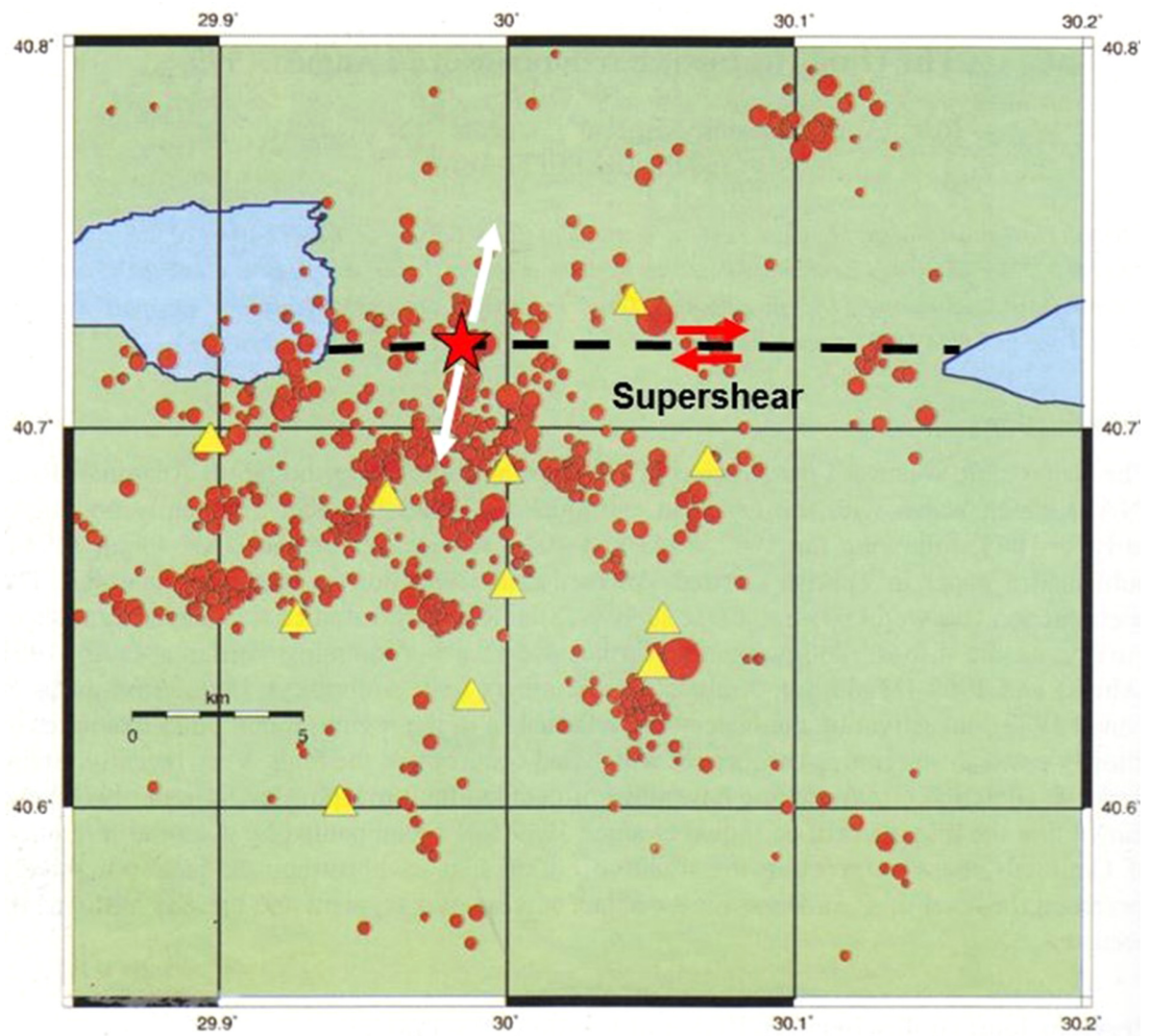

Figure 2. Map of the seismic activity of the Izmit cluster in the Summer of 1984. The smallest circles correspond to earthquakes of $M \sim 0.5$, the largest to earthquakes of $M \sim 3$. Triangles are seismic stations. The dashed line shows the location of the NAF. The red star is the future Izmit epicentre. White arrows show the direction of crustal extension determined from focal mechanisms and shear wave anisotropy (Fig. 3). This extension is the motor of the swarm activity. Red arrows show the directions of slip during the 1999 earthquake. Modified from Evans et al. (2000).

none of this activity seems associated with the NAF which is now well known to be particularly straight and vertically dipping in this region. This is confirmed by the focal mechanisms of the events, largely dominated by normal faulting (Lowell et al. 1987, Fig. 3a). As these authors concluded at the time: 'The main driving force of these swarm events is the tensional stress which is constrained to a subhorizontal direction $N 180^{\circ} \mathrm{E}$ to $N 190^{\circ} \mathrm{E}$.

Another characteristic of the cluster observed during the 1980s experiments is that: 'Almost all shear waves displayed shear wave splitting. The polarization of the faster split shear waves are within $\pm 20^{\circ}$ of $N 100^{\circ}$ E for all arrivals at all recording sites' (Booth et al. 1985; Crampin \& Booth 1985, Fig. 3b)
What focal mechanisms and shear wave splitting show is that the crust in the Izmit swarm area was, before the earthquake, under intense tensional stress oriented in a nearly NS direction. This direction of extension is encountered throughout the AegeanWestern Anatolia domain and results from the rapid rollback of the Hellenic subduction to the south (McKenzie 1978; Le Pichon \& Angelier 1979). The presence of a cluster of extensional seismicity in the Izmit region suggests a localization there of intense crustal extension. The direction of this extension nearly perpendicular to the NAF implies that the normal compressive stress acting on the fault was particularly weak in this zone. As no other seismic cluster of comparable strength was present along 
(a)

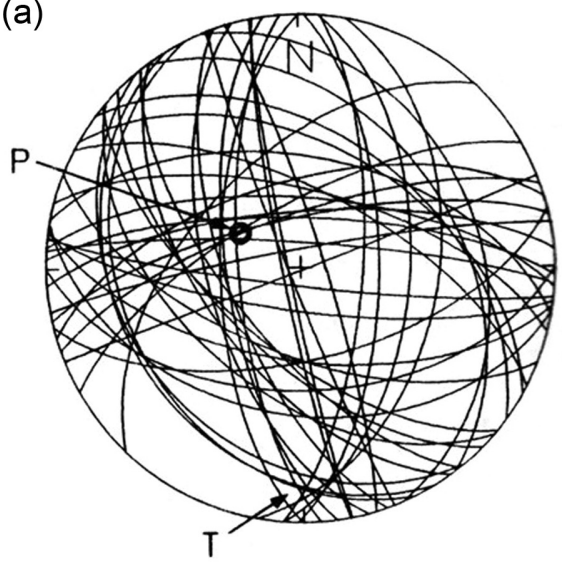

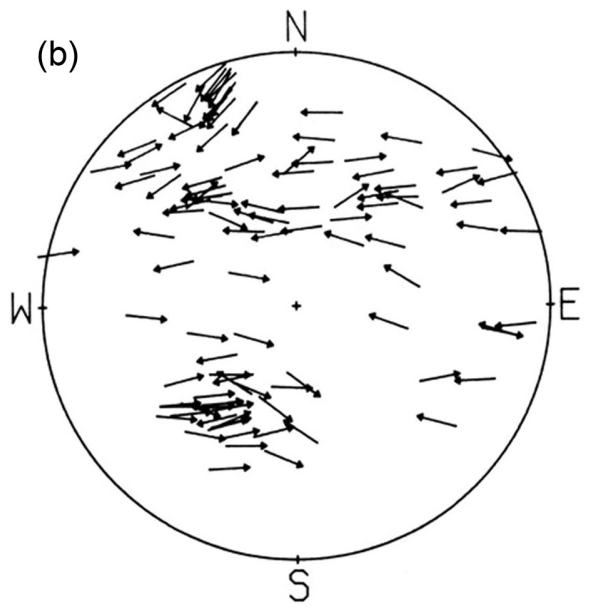

Figure 3. Characteristics of the Izmit cluster observed during the 1980s experiments. (a) Superposition of fault-plane solutions with their common tension ( $T$ ) and compression $(P)$ axes (Lowell et al. 1987). (b) Horizontal polarization of first $S$ arrival at local stations (Booth et al. 1985).
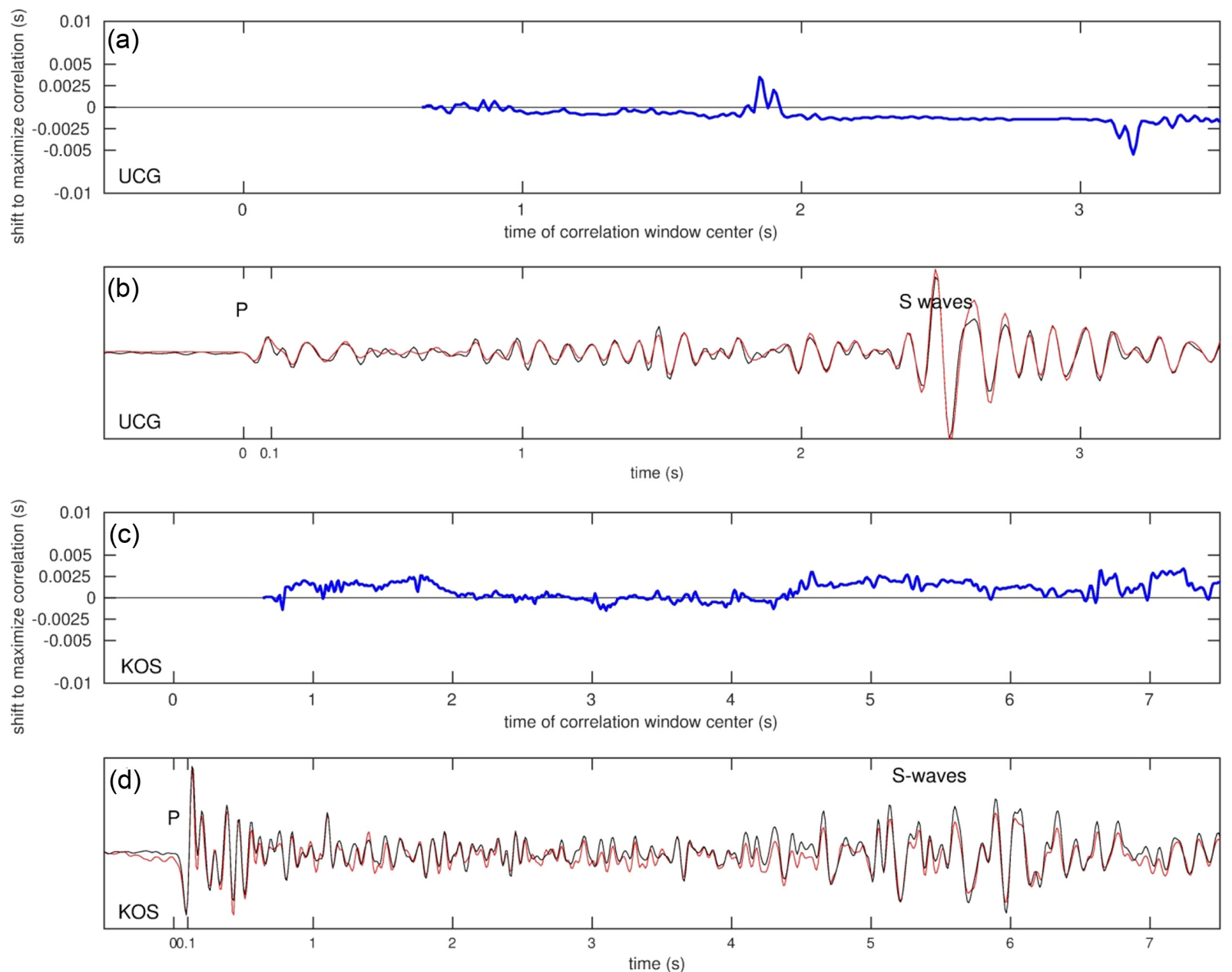

Figure 4. Cross-correlation between the records of two $M>2$ foreshocks at the two closest stations from the epicentre UCG (top panel) and KOS (bottom panel). The two events are \#6 and \#13 in Bouchon et al. (2011) and Ellsworth \& Bulut (2018). (a, c) Evolution of the time shift which maximizes the correlation between the waveforms of the two foreshocks. The correlation is done over a moving window 128 points long (1.28 s). The first window begins at the $P$-wave arrival and corresponds to the origin of the time axis. Subsequent time shifts are measured relatively to this first window. The time shift is obtained by interpolating the correlation peak at each time step. (b, d) Superposition of the records of the two foreshocks at each station. One of the records has been shifted in time (in the Fourier domain) by the time increment which maximizes the cross-correlation of the two signals. The $P$ arrivals correspond to the origin of the time axis. The non-zero amplitude before the $P$ arrivals shows the noise level of the records. 
(a)

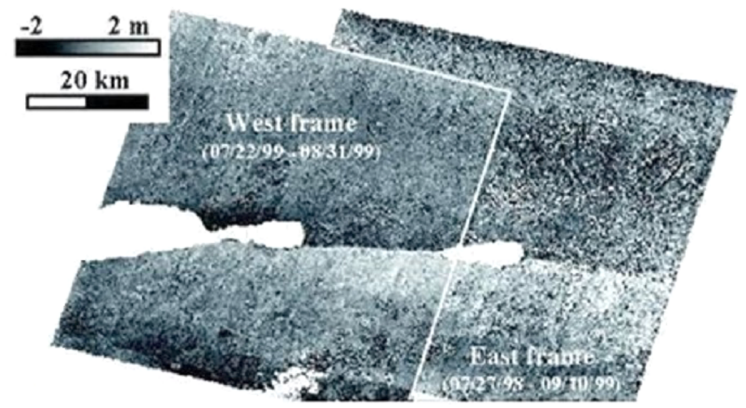

(b)

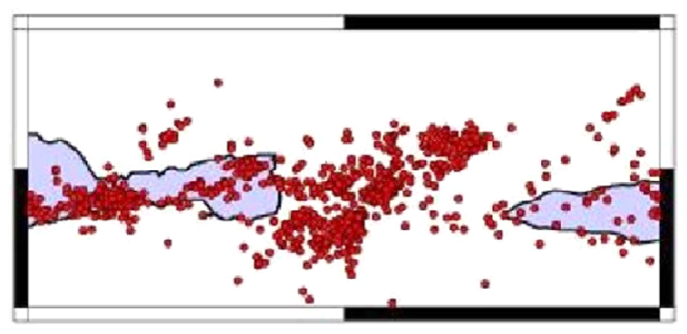

Figure 5. (a) Displacement map of the Izmit rupture along the supershear segment obtained by pixel correlation of Spot images (Michel \& Avouac 2002). (b) Aftershock locations in the same region (Bouchon \& Karabulut 2008).

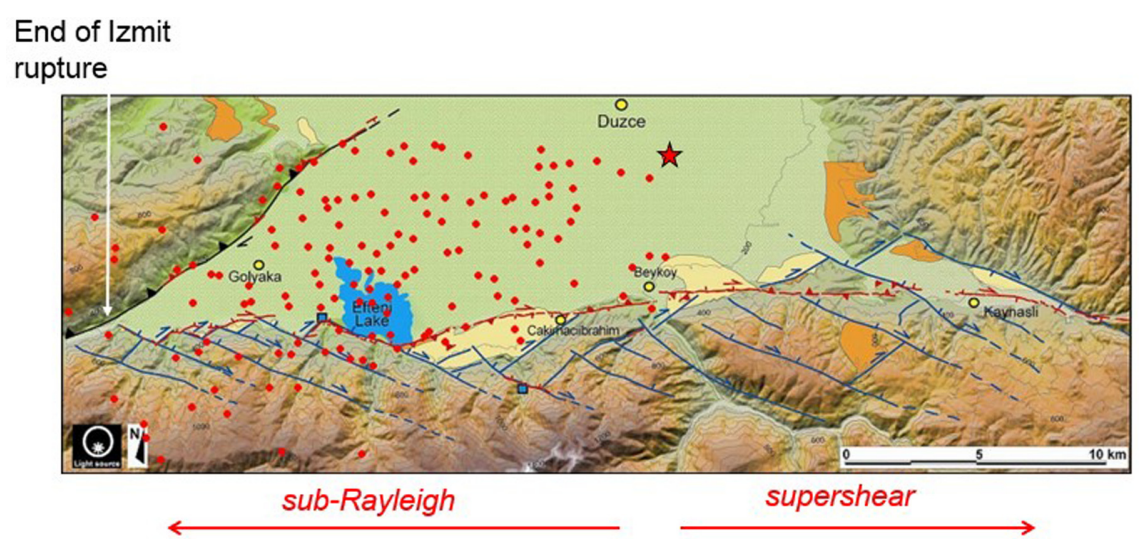

Figure 6. Map of the surface rupture of the Düzce earthquake (discontinuous red line). Secondary fault structures anterior to the NAF are in blue (Pucci et al. 2006b). The fault dips $\sim 65^{\circ} \mathrm{N}$ and the star is the epicentre. Red dots show the locations of $1 \mathrm{~d}$ of early aftershocks (Magnitude of completeness 1 ; Milkereit et al. 2000). Rupture was bilateral and propagated at sub-Rayleigh velocity westward from the epicentre and supershear velocity eastward. (Modified from Pucci et al. 2006b).
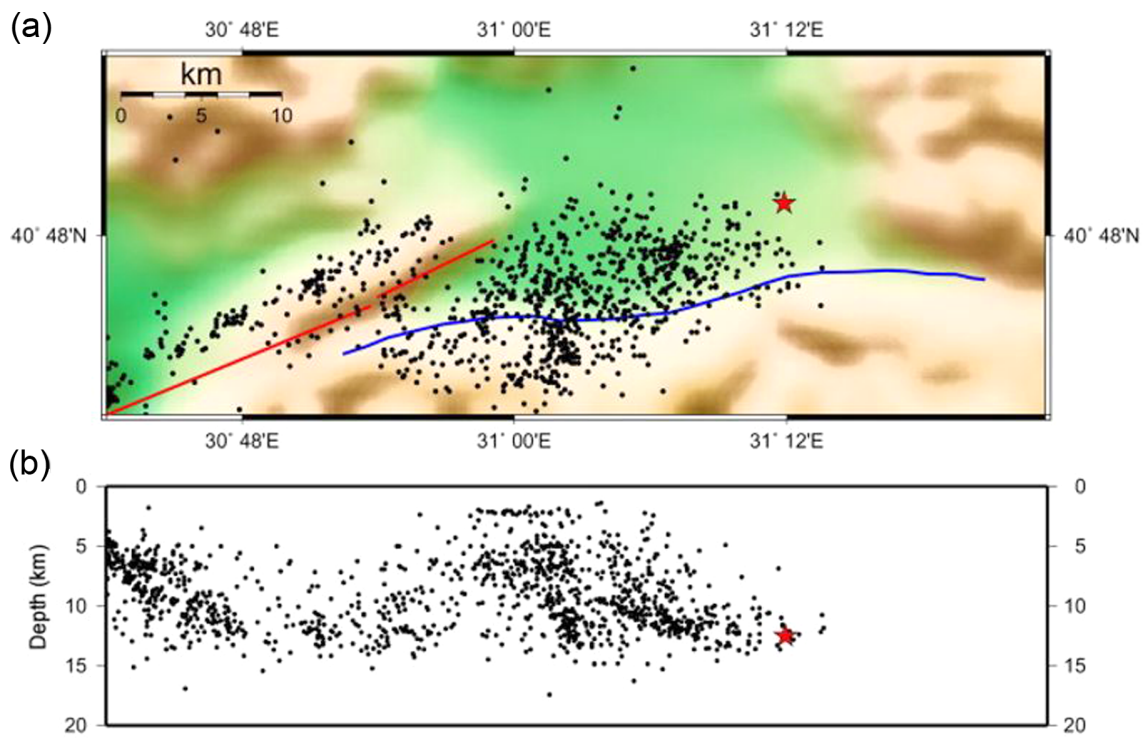

Figure 7. (a, b) Aftershocks of the Izmit earthquake in the $25 \mathrm{~d}$ preceding the Düzce earthquake (Görgün et al. 2009). The red and blue lines show the simplified traces of the Izmit and Düzce ruptures. The red star is the Düzce hypocentre. (After Görgün et al. 2009).

the 200 -km-long segment which ruptured in 1999 (Fig. 1), it seems logical that the normal compressive stress was the lowest there, making this zone the most probable nucleation site for the earthquake.

\section{THE IZMIT FORESHOCKS}

The closest station to the epicentre, UCG located only $13 \mathrm{~km}$ away (Fig. 1), was triggered into recording $45 \mathrm{~min}$ before the earthquake. 


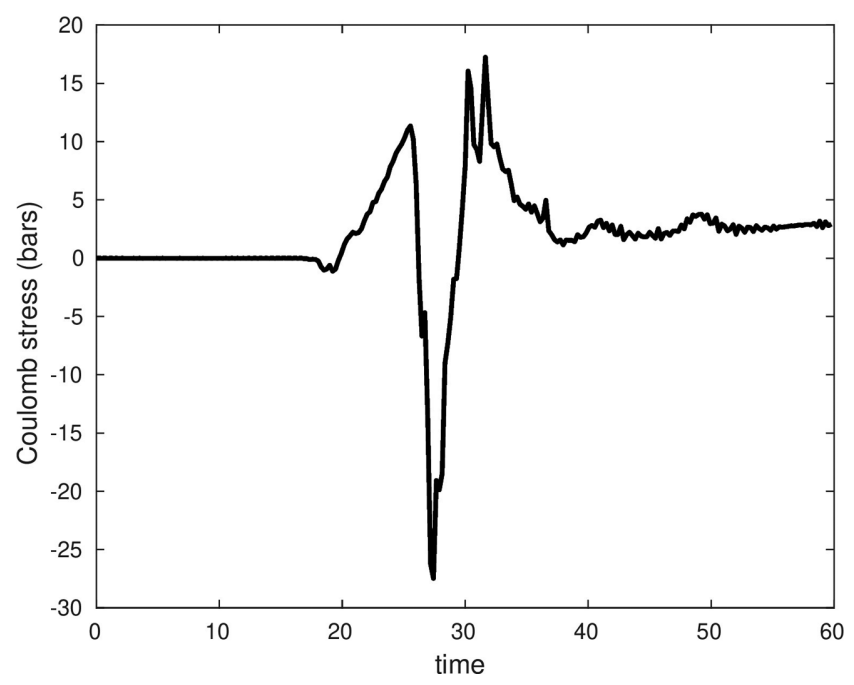

Figure 8. Calculated dynamic and static Coulomb stress loading produced by the Izmit earthquake on the Düzce fault at the Düzce hypocentre. The calculation is made using the discrete wavenumber method and the Izmit faulting model of Bouchon et al. (2001).

18 events have been identified on records of this station and 26 additional events were detected by template matching (Bouchon et al. 2011). The similarity of the 18 waveforms shows that they were originating from the same zone while the similarity of their spectra supports that they were produced by the repeating slip of the same asperity. A comparison of the $S-P$ times of the largest foreshock, recorded at several stations, with the $S-P$ time of the main shock shows that, within the time resolution of the data $(0.01 \mathrm{~s})$, the foreshock signals were coming from a location less than $100 \mathrm{~m}$ away from the future hypocentre.

The next closest station to the epicentre, KOS, was located $\sim 38$ $\mathrm{km}$ away from the epicentre. This station recorded only the largest foreshocks. While UCG lies in a direction almost perpendicular to the fault relatively to the hypocentre, KOS is more in-line with the fault strike. It is thus interesting to compare cross-correlations of the same events at both stations. This is presented in Fig. 4. The two events considered are two of the largest foreshocks $(M>2)$. They occurred close in time (less than 8 min apart) in the middle of the foreshock sequence. Because of the noise level at KOS, the records are low pass filtered at $12 \mathrm{~Hz}$, which is about the corner frequency of their spectra (Bouchon et al. 2011). At the two stations the difference in $S-P$ times between the two foreshocks is within $\sim 0.002 \mathrm{~s}$. This time difference, translated into distance, implies that the two stations see the centre of radiation of the two foreshocks within $\sim 17 \mathrm{~m}$ from each other. This is considerably smaller than the typical source size of $M>2$ events $(>100 \mathrm{~m}$ ) and is indeed much smaller than the source radius inferred in another study (Ellsworth \& Bulut 2018) for the largest one of these two events (74 $\mathrm{m}$ or $111 \mathrm{~m}$ depending on the source model they use). According to these authors estimates, the separation of the centre of radiation of the two foreshocks should be of the order of $100 \mathrm{~m}$ for the two ruptures not to overlap. This would result in a difference in $S-P$ times between the two foreshocks of Fig. 4 in excess of $0.01 \mathrm{~s}$, much higher than what is observed. This implies that the ruptured areas of the two foreshocks mostly overlap, indicating that the same asperity is involved in the two shocks. Slight differences in the two signals are to be expected as the two rupture histories likely differ, such as the location where rupture initiates on the patch. These considerations may seem to be details, but they are important as they may lead to two different mechanics of foreshock generation. In the cascade model of Ellsworth \& Bulut (2018), rupture of a fault patch loads an adjacent fault patch causing it to break. What we observe here is not the break of two separate patches, even adjacent, but the repeated break, 8 min apart, of what is mostly the same patch of fault. The repeating rupture of the same patch at a few minutes interval supports that the fault is locally slipping aseismically and that this slip is reloading the asperity. The hypocentral location at $\sim 17 \mathrm{~km}$ depth places this aseismic slip at the bottom of the seismogenic crust, near the ductile-to-brittle transition zone.

The foreshock pattern of the Izmit earthquake - the repeated slip of the same patch of fault - may seem unusually simple in comparison to foreshocks observed in many earthquakes. However, this pattern is similar to the one which has long been observed in rock mechanics experiments, going back to the pioneering work of Brace \& Byerlee (1966). It is the well-known stick-and-slip phenomenon which takes place during frictional sliding when two bodies in contact are forced to slip past each other (Burridge \& Knopoff 1967). In the rock experiments the sample is pre-cut along a plane. At the scale of the sample, friction conditions along the contact are nearly uniform. As the load exerted on the sample by outside forces (the press) is continuously and regularly increased, slip occurs through a succession of repeated bursts. At Izmit, nucleation took place on what has been repeatedly described by field geologists as a very simple fault segment. Analyzing the satellite images of rupture in this zone, Michel \& Avouac (2002) write 'The surface ruptures associated with the Izmit earthquake seem remarkably simple'. The very linear geometry of the fault (Fig. 5a) and the narrow continuous trace of its rupture scar are strong indications that friction conditions are remarkably homogeneous on the nucleation segment. These characteristics that will lead to the supershear rupture of this segment (Bouchon et al. 2001) also imply that few frictional asperities were present. This absence of strong asperities is also supported by the geographic distribution of aftershocks which cluster on offthe-fault secondary structures (Fig. 5b) rather than on the fault itself as would be expected if asperities were present (Bouchon \& Karabulut 2008). This is also mechanically consistent with the remarkable observation that this whole segment kept creeping at a high rate for more than a decade after the earthquake (Çakir et al. 2012) and is still creeping $20 \mathrm{yr}$ later (Aslan et al. 2019). The presence of a very planar fault and of particularly homogeneous friction conditions make the analogy with the stick-slip lab experiments logical. Other analogies with natural phenomena involving frictional sliding exist: The rapid stick-slip of the same interface patch has been observed during the down-sliding of glaciers (Danesi et al. 2007; Zoet et al. 2012; Helmstetter et al. 2015); seismic foreshocks preceding landslide failure have been interpreted as repeated stick-slip of the same patch (Yamada et al. 2016).

\section{THE LOCATION OF THE DÜZCE EPICENTRE}

The $M 7.1$ Düzce earthquake occurred nearly three months after the Izmit earthquake and extended the Izmit rupture eastward by $\sim 40 \mathrm{~km}$ (Fig. 6). Although the two ruptures lay closely contiguous, the earthquake began $\sim 20 \mathrm{~km}$ away from the end of the Izmit rupture, near the middle of the new broken segment. Three sets of observations help understand why rupture began there rather than next to the previously broken segment, where static and dynamic stresses were higher. The first one comes from the rupture velocity: 

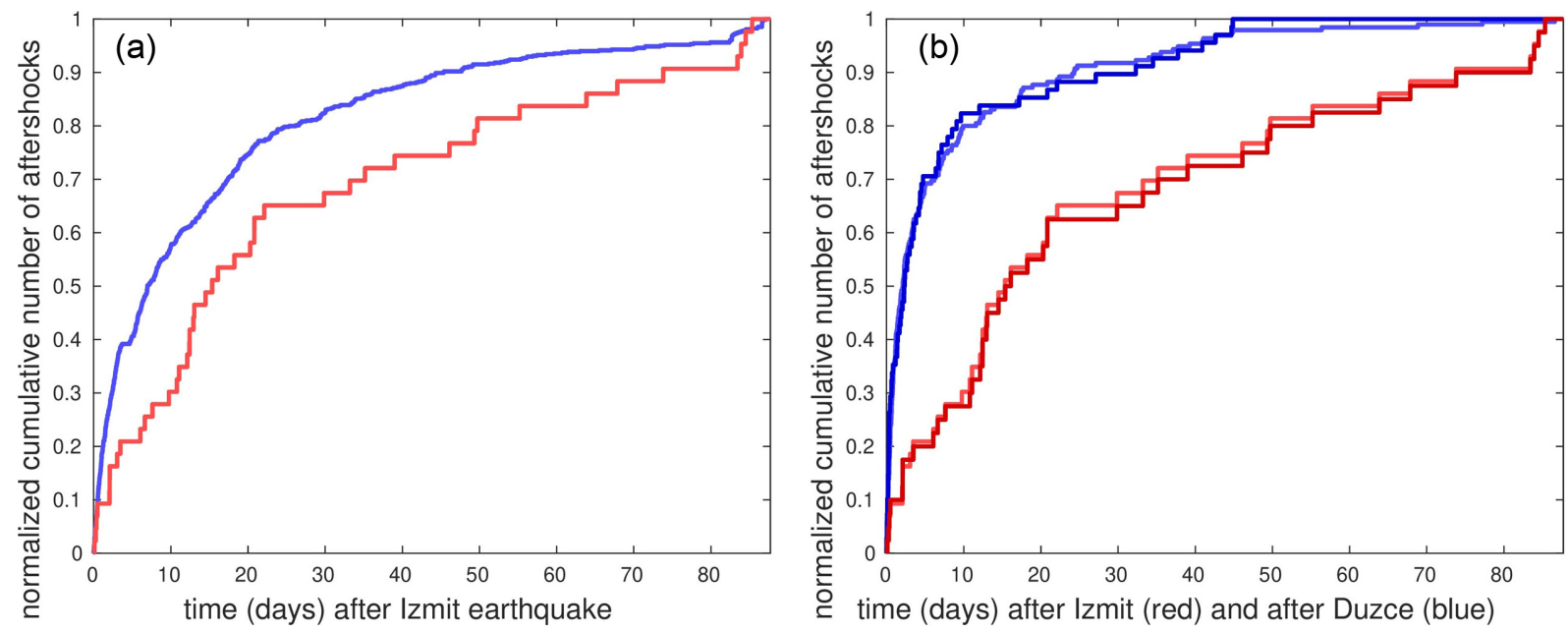

Figure 9. Compared time evolutions of aftershocks. (a) Evolution of the number of aftershocks $(M>2.8)$ of the Izmit earthquake during the $87 \mathrm{~d}$ between the two earthquakes. Two segments of the NAF are considered: the Izmit segment which had just ruptured (in blue) and the adjacent Düzce segment which was about to rupture (red). (b) Compared evolutions of the number of aftershocks on the Düzce segment: (1) following the Izmit earthquake which loaded this segment (red) and (2) following the Düzce earthquake which ruptured it (blue). $M>2.8$ events are in lighter colour, $M>3$ events in darker colour.

While rupture propagated westward on the segment between the new epicentre and the end of the previous Izmit rupture at subRayleigh velocity, it propagated eastward on the other segment at supershear speed (Bouchon et al. 2001; Bouin et al. 2004; Konca et al. 2010). The second observation comes from the morphology of the Düzce rupture (Pucci et al. 2006a,b). Citing Pucci et al: 'Overall, we recognized two different sections of the Düzce segment: a western section where the coseismic fault trace has a staircase trajectory; an eastern section, where the coseismic fault trace shows a straight trajectory'. The third observation comes from the location of the Izmit aftershocks which occurred in the Düzce region in the period between the two earthquakes and shows a remarkable contrast between a western segment densely illuminated and an eastern segment devoid of aftershocks (Milkereit et al. 2000; Görgün et al. 2009). These three observations combined on Fig. 6 are consistent with each other and show the existence of a remarkable contrast in geometry and mechanics between the two segments of the Düzce rupture. The complex geometry of the western segment, adjacent to the Izmit rupture, implies a very heterogeneous state of stress and friction, with a mix of strong and weak zones. While weak zones will easily break in aftershocks, the strong zones will tend to prevent any event to become very large. On the opposite the simple geometry of the eastern segment suggests a relatively homogeneous state of friction on this part of the fault. This type of strike-slip segment is prone to supershear rupture (Archuleta 1984; Bouchon et al. 2001; Robinson et al. 2010) and the absence of zones where friction is weak makes it unlikely to host aftershocks.

The location of the Düzce epicentre is precisely at the juncture between these two segments. It lies at the very location where the simple segment is the closest to the Izmit rupture and therefore where this simple segment was the most loaded in stress by the Izmit earthquake. Once rupture began on this simple segment of relatively homogeneous friction, no strong asperity was there to arrest the rupture. In a way, as seen remarkably on the maps of Milkereit et al. (2000) and Görgün et al. (2009, Figs 6 and 7), Düzce was the first significant aftershock of Izmit to occur on the simple (supershear) segment of the fault. One question remains: Why did it take three months to load this edge of the simple segment?

\section{THE 3 MONTHS DELAY BETWEEN THE TWO EARTHQUAKES}

A straightforward calculation shows that the Izmit earthquake produced a peak dynamic stress load of about 30 bars at the Düzce hypocentre and increased the static Coulomb stress there by about 3 bars (Fig. 8).

Within a few hours of the Izmit earthquake, three of its largest aftershocks $(M \geq 4)$ occurred on the complex western segment of the Düzce fault (Aktar \& Örgülü 2001), consistent with the large dynamic stress load magnified there by the directivity effect of the propagating rupture. After this rapid activation, a diffused pattern of activity emerged with aftershocks spread surprisingly evenly throughout the whole western segment (Milkereit et al. 2000; Görgün et al. 2009). This geographic pattern stayed basically unchanged for 3 months and no clear migration of seismicity was observed (Görgün et al. 2009).

The comparison of the evolutions of Izmit aftershock activity on this yet unruptured Düzce segment and on the ruptured Izmit segment itself (Fig. 9a) shows that while the broken Izmit segment underwent a classical Omori type relaxation with activity progressively tapering off, activity stayed more sustained on the Düzce segment and had not tapered off 3 months after the Izmit earthquake. This supports that something more complex than elastic stress relaxation was occurring on the Düzce segment. The remarkable correlation observed by Perfettini \& Avouac $(2004,2007)$ between the afterslip of several well-recorded earthquakes and their aftershock decay led them to propose that afterslip is the motor of aftershocks. Applying their model here would indicate that while afterslip was relaxing as expected on and below the ruptured Izmit segment, some amount of slow slip was still loading the Düzce segment 3 months after the Izmit earthquake.

The comparison with the evolution of aftershock activity on this segment after its November rupture (Fig. 9b) supports, we believe, this interpretation. The very rapid aftershock decay which took place after its rupture is in contrast to the slow decay of activity which followed the Izmit loading. This comparison shows that what controls the Omori parameters of aftershock decay is not an intrinsic property of a fault. Applying Perfettini and Avouac model, the rapid decay which followed this segment rupture suggests that little slow 
slip occurred on and below the fault after it ruptured. In contrast, the slow decay observed after the Izmit loading supports the presence during this interearthquake period of a lasting phase of slow slip. This would explain the surprising observation that 2 months after the Izmit break, the Düzce fault was the seat of more aftershocks than it was 2 months after its own breaking (Fig. 9b).

Inversion of GPS data shows that in the weeks following the Izmit earthquake, large afterslip occurred on the easternmost segment of the Izmit rupture (Reilinger 2000; Bürgmann et al. 2002). Afterslip on this segment, known as the Karadere segment, was not in the shallow crust where rupture had occurred but down-dip from it, below the seismogenic crust (Reilinger 2000; Bürgmann et al. 2002). In their study of Izmit afterslip Bürgmann et al. say: 'The highest slip is inferred below the Karadere fault segment immediately west of the eventual Düzce rupture'. Their inversion shows that the entire length $(\sim 30 \mathrm{~km})$ of this easternmost segment was slipping below the seismogenic zone. Citing them further they say: 'Shallow afterslip decayed rapidly within about 1 month, whereas slip deep below the rupture continued until the time of the Düzce event'. The presence or not of some afterslip on the Düzce segment itself after the Izmit earthquake is difficult to assess because, citing Hearn et al. (2002): 'Neither of these possibilities may be ruled out by GPS data from east of the Izmit rupture: there are too few reliable measurements to adequately constrain the distribution of afterslip in this area'. The presence of some afterslip there would however be consistent with inversion results of Ergintav et al. (2009). The rapid decay we observe of rupture zone aftershocks after the Düzce earthquake and its interpretation in terms of no or little afterslip following the earthquake is in agreement with the InSar study of Çakir et al. (2003) who write: 'in contrast to the 17 August 1999 Izmit event, a fast dynamic after-slip does not seem to have occurred following the Düzce earthquake'.

\section{DIS CUSSION}

The seismic activities which took place before, during, and after the two well-instrumented 1999 earthquakes shed some light on some of the mechanical aspects of the nucleation sequence. A schematic description of the rupture chronology of the NAF in 1999 may be attempted: (1) the location of the Izmit epicentre was constrained by the localization there of nearly north-south crustal extension releasing the normal stress on the east-west running strike-slip NAF. (2) Because at this location the fault geometry is remarkably planar, indicative of near-homogeneous friction conditions, the nucleation phase could be seen relatively clearly. Its seismic signature was the repeated sliding of what was basically one asperity, in a way similar to the frictional sliding behaviour observed in ideallysimple laboratory friction conditions. (3) This stick-slip accelerated in time, irregularly, for $45 \mathrm{~min}$, supporting the concomitant presence of slowly accelerating aseismic slip around the asperity. (4) Once nucleated, rupture propagated at supershear speed on this straight homogeneous segment. (5) Reaching the end of this simple segment, rupture velocity diminishes to sub-Rayleigh velocity. The arrest of rupture to the east occurred when encountering a $\sim 20-\mathrm{km}-$ long segment with $a \sim 20^{\circ}$ change in strike and a very complicated ('stair-case' like) geometry. (6) Aftershock activity suggests that the loading of this complex segment continued at depth during the 3 months period separating the two earthquakes. (7) The restart of rupture then occurred at the junction between this complex segment and the straight segment adjacent to it. (8) Once slip began on this straight segment, rupture propagated again at supershear speed, stopping only when reaching the end of this branch of the NAF.

The location of the Izmit epicentre near a cluster of extensional events is reminiscent of the epicentre locations of the 1943 and 1944 earthquakes, two major events in the western migration of large ruptures along the NAF (Dewey 1976; Toksöz et al. 1979; Stein et al. 1997). Like Izmit, these two earthquakes nucleated near one of the most active extensional clusters present along the NAF (Durand et al. 2010). As the roll-back of the hellenic subduction is the motor of Aegean-Anatolia extension (McKenzie 1978; Le Pichon \& Angelier 1979), this observation supports that this rollback, occurring $\sim 1000 \mathrm{~km}$ away, indirectly controlled the location of the epicentres of three of the major earthquakes in the 1939-1999 sequence.

\section{CONCLUSION}

We have tried to show through the study of the nucleation of these two large well-recorded earthquakes that a nucleation process which obeys some mechanical logic is at work before the catastrophic rupture occurs. Elements of this logic can be retrieved from different domains of study, here field geology, seismicity, rupture dynamics, space geodesy and tectonics. When present, foreshocks are just one particular signature of a larger physical process. When considered alone, they rarely allow a distinct identification of a nucleation phase. In many ways the reason that we so often attribute to hazard the occurrence of an earthquake at a particular place and time, dismissing any hope to ever predict, may simply hide our present lack of knowledge and understanding of the physical processes involved.

\section{REFER E N CES}

Aktar, M. \& Örgülü, G., 2001. Study of strong aftershocks of Izmit and Düzce earthquake sequence using regional moment tensor inversion, in Seismotectonics of the North-Western Anatolia-Aegean and Recent Turkish Earthquakes, Istanbul Technical Univeristy, pp. 72-77.

Akyüz, H.S. et al., 2002. Surface rupture and slip distribution of the 12 November 1999 Düzce earthquake (M7.1), North Anatolian Fault, Bolu, Turkey, Bull. seism. Soc. Am., 92, 61-66.

Archuleta, R.J., 1984. A faulting model for the 1979 Imperial Valley earthquake, J. geophys. Res., 89, 4559-4585.

Aslan, G., Lasserre, C., Cakir, Z., Ergintav, S., Özarpaci, S., Dogan, U., Bilham, R. \& Renard, F., 2019. Shallow creep along the 1999 Izmit earthquake rupture (Turkey) from GPS and high temporal resolution interferometric synthetic aperture radar data (2011-2017), J. geophys. Res., 124(2), 2218-2236.

Barka, A. et al., 2002. The surface rupture and slip distribution of the 17 August 1999 Izmit earthquake, Bull. seism. Soc. Am., 92, 43-60.

Booth, D.C., Crampin, S., Evans, R. \& Roberts, G., 1985. Shear wave polarization near the North Anatolian Fault: I. Evidence for anisotropyinduced shear-wave splitting, Geophys. J. R. astr. Soc., 83, 75-92.

Bouchon, M., Bouin, M.P., Karabulut, H., Toksöz, M.N., Dietrich, M. \& Rosakis, A.J., 2001. How Fast is rupture during an earthquake? New insights from the 1999 Turkey earthquakes, Geophys. Res. Lett., 28, $2723-$ 2726.

Bouchon, M. \& Karabulut, H., 2008. The aftershock signature of supershear earthquakes, Science, 320, 1323-1325.

Bouchon, M., Karabulut, H., Aktar, M., Ozalaybey, S., Schmittbuhl, J. \& Bouin, M.P., 2011. Extended nucleation of the $1999 \mathrm{M}_{\mathrm{w}} 7.6$ Izmit earthquake, Science, 331, 877-880.

Bouin, M.P., Bouchon, M., Karabulut, M. \& Aktar, M., 2004. Rupture process of the 12 November 1999, Düzce (Turkey) earthquake deduced from strong motion and GPS measurements, Geophys. J. Int., 159, 207211. 
Brace, W.F. \& Byerlee, J.D., 1966. Stick-slip as a mechanism for earthquakes, Science, 153, 990-992.

Bürgmann, R. et al., 2002, Time-dependent distributed afterslip on deep below the Izmit earthquake rupture, Bull. seism. Soc. Am., 92, 126-137.

Burridge, R. \& Knopoff, L. 1967. Model and theoretical seismicity, Bull. seism. Soc. Am., 57, 341-371.

Çakir, Z., Barka, A., de Chabalier, J.B., Armijo, R. \& Meyer, B., 2003. Kinematics of the November 12, $1999(\mathrm{Mw}=7.2)$ Düzce earthquake deduced from SAR interferometry, Turkish J. Earth Sci., 12, 105-118.

Çakir, Z., Ergintav, S., Özener, H., Dogan, U., Akoglu, A.M., Meghraoui, M. \& Reilinger, R., 2012. Onset of aseismic creep on major strike-slip faults, Geology, 40, 1115-1118.

Crampin, S., Evans, R. \& Uçer, S.B., 1985. Analysis of records of local earthquakes: the Turkish Dilatancy Projects (TDP1 and TDP2), Geophys. J. R. astr. Soc., 83, 1-16.

Crampin, S. \& Booth, D.C., 1985. Shear wave polarization near the North Anatolian Fault: II. Interpretation in terms of crack-induced anisotropy, Geophys. J. R. astr. Soc., 83, 61-73.

Danesi, S., Bannister, S. \& Morelli, A., 2007. Repeating earthquakes from rupture of an asperity under an Antarctic outlet glacier, Earth planet. Sci. Lett., 253, 151-158.

Dewey, J.W., 1976. Seismicity of Northern Anatolia, Bull. seism. Soc. Am., 66, 843-865.

Durand, V. et al., 2010. Seismic interaction and delayed triggering along the North Anatolian Fault, Geophys. Res. Lett., 37, L18310, doi:10.1029/2010GL044688.

Ellsworth, W.F. \&Bulut, 2018. Nucleation of the 1999 Izmit earthquake by a triggered cascade of foreshocks, Nat. Geosci., 11, 531-535.

Ergintav, S. et al., 2009. Seven years of postseismic deformation following the $1999 \mathrm{M}=7.4$ and $\mathrm{M}=7.2$ Izmit-Düzce earthquake sequence, $J$. geophys. Res., 114, B07403.

Evans, R., Beamish, D., Crampin, S. \& Uçer, S.B., 1987. The Turkish Dilatancy Project (TDP3): multidisciplinary studies of a potential earthquake source region, Geophys. J. R. astr. Soc., 91, 265-286.

Evans, R., Sargeant, S., Ucer, S.B. \& Komut, T. , the UK EEFIT Team, 2000. The Izmit (Kocaeli) earthquake of 17 August 1999, in The 1999 Izmit and Düzce Earthquakes: Preliminary Results, pp. 137-146, edsBarka et al., Istanbul Technical University.

Görgün, E., Zang, A., Bohnhoff, M., Milkereit, C. \& Dresen, G., 2009. Analysis of Izmit aftershocks 25 days before the November $12^{\text {th }} 1999$ Düzce earthquake, Turkey, Tectonophysics, 474, 507-515.

Hearn, E.H., Bürgmann, R. \& Reilinger, R.E., 2002. Dynamics of Izmit earthquake postseismic deformation and loading of the Düzce earthquake hypocenter, Bull. seism. Soc. Am., 92, 172-193.

Helmstetter, A., Nicolas, B., Comon, P. \& Gay, M., 2015. Basal icequakes recorded beneath an Alpine glacier (Glacier d'Argentiere, MontBlanc, France): evidence for stick-slip motion, J. geophys. Res., 120, 379-401.

Konca, O., LePrince, S., Avouac, J.P. \& Helmberger, D.V., 2010. Rupture process of 1999, $\mathrm{M}_{\mathrm{w}}$ 7.1 Duzce earthquake from joint analysis of SPOT,
GPS, InSAR, strong-motion and teleseismic data: a supershear rupture with variable rupture velocity, Bull. seism. Soc. Am. 100, 267-287.

Le Pichon, X. \& Angelier, J., 1979. The hellenic arc and trench system: a key to the neotectonic evolurion of the eastern Mediterranean area, Phil. Trans. R. Soc. Lond., 300, 357-372.

Lowel, J., Crampin, S., Evans, R. \& Uçer, B., 1987. Microearthquakes in the TDP swarm, Turkey: clustering in time and space, Geophys. J. R. astr. Soc., 91, 313-330.

McKenzie, D., 1978. Active tectonics of the Alpine-Hymalayan belt: the Aegean Sea and surrounding regions, Geophys. J. R. astr. Soc., 55, $217-$ 254.

Michel, R. \& Avouac, J.P., 2002. Deformation due to the 17 August 1999 Izmit, Turkey, earthquake measured from SPOT images, J. geophys. Res., 107, B4.

Milkereit, C. et al., 2000. Preliminry aftershock analysis of Mw $=7.4$ Izmit and $\mathrm{Mw}=7.1$ Düzce earthquake in Western Turkey, in The 1999 Izmit and Düzce Earthquakes: Preliminary Results, pp. 179-187, edsBarka et al., Istanbul Technical University.

Perfettini, H. \& Avouac, J.P., 2004. Postseismic relaxation driven by brittle creep: a possible mechanism to reconcile geodetic measurements and the decay rate of aftershocks, application to the Chi-Chi earthquake, Taiwan, J. geophys. Res., 109, B02304.

Perfettini, H. \& Avouac, J.P., 2007. Modeling afterslip and aftershocks following the 1992 Landers earthquake, J. geophys. Res., 112, B07409.

Pucci, S., Palyvos, N., Zabci, C., Pantosti, D. \& Barchi, M., 2006a. Coseismic ruptures and tectonic landforms along the Düzce segment of the North Anatolian Fault Zone (Ms 7.1, November 1999). J. geophys. Res., 111(B6),

Pucci, S., Pantosti, D., Barchi, M. \& Palyvos, N., 2006b. Evolution and complexity of the seismogenic Düzce fault zone (Turkey) depicted by coseismic ruptures, plio-quaternary structural pattern and geomorphology, in Proceedings of the Tectonics of Strike-Slip Restraining and Releasing Bends, Geological Society of London, London, UK.

Reilinger, R., 2000. Coseismic and postseismic fault slip for the 17 August 1999 M = 7.5 Izmit, Turkey earthquake, Science, 289, 1519-1524.

Robinson, D.P., Das, S. \& Searle, M.P., 2010. Earthquake fault superhighways, Tectonophysics, 493, 236-243.

Stein, R.S., Barka, A.A. \& Dieterich, J.H., 1997. Progressive failure on the North Anatolian fault since 1939 by earthquake stress triggering, Geophys. J. Int., 128, 594-604.

Toksöz, M.N., Shakal, A.F. \& Michael, A.J., 1979. Space-time migration of earthquakes along the N. Anatolian fault zone and seismic gaps, Pure appl. Geophys., 117, 1258-1270.

Yamada, M., Mori, J. \& Matsushi, Y., 2016. Possible stick-slip behavior before the Rausu landslide inferred from repeating seismic events, Geophys. Res. Lett., 43, 9038-9044.

Zoet, L.K., Anandakrishnan, S., Alley, R.B., Andrew, A., Nyblade, A.A. \& Wiens, D.A., 2012. Motion of an Antarctic glacier by repeated tidally modulated earthquakes, Nat. Geosci., 5, 623-626. 